\title{
ENERGY DISPERSIVE X-RAY MICROANALYSIS OF LAMINATED SEDIMENTS FROM LAKE VALKIAJÄRVI, FINLAND
}

\author{
TUOMO ALAPIETI and MATTI SAARNISTO
}

\begin{abstract}
ALAPIETI T. AND SAARNISTO M. 1981: Energy dispersive X-raymicroanalysis of laminated sediments from Lake Valkiajärvi, Finland. Bull. Geol. Soc. Finland 53-1, 3-9.

Energy dispersive X-ray spectrometry is applied to the study of thinly laminated organic sediments of the iron-meromictic Lake Valkiajärvi, Finland. Si, Fe, Ca, K, S, (and $\mathrm{Cl}$ as an artefact) are present in detectable quantities. It is concluded that the main reason for the occurrence of such annual laminations (i.e. varves) in this lake is the seasonal variation in the deposition of mineral matter. Iron remains low throughout the year and does not play any important role in varve formation.
\end{abstract}

Tuomo Alapieti and Matti Saarnisto, Department of Geology, University of Oulu, SF-90570 Oulu 57, Finland.

\section{Introduction}

Sediments from the $25 \mathrm{~m}$ deep basin of Lake Valkiajärvi, Finland, were found to contain thin laminations each comprising a light-dark couplet averaging $0.3 \mathrm{~mm}$ in thickness (Fig. 1). The laminations are believed to be annual, i.e. true varves, which reflect seasonal variations in mineral matter accumulation. It has been suggested (Koivisto \& Saarnisto 1978, Saarnisto 1978, 1979) that the light layers represent mainly mineral matter deposited in early summer after the melting of the ice. The proportion of mineral matter and its particle size decrease upwards through each lamina, while the proportion of dark organic matter increases towards the winter. The boundary between the dark winter layer and the light spring layer is sharply-defined.
Lake Valkiajärvi is meromictic, i.e. permanently chemically stratified, with a very high iron content in the bottom water (Meriläinen 1970). The sediments of another iron-

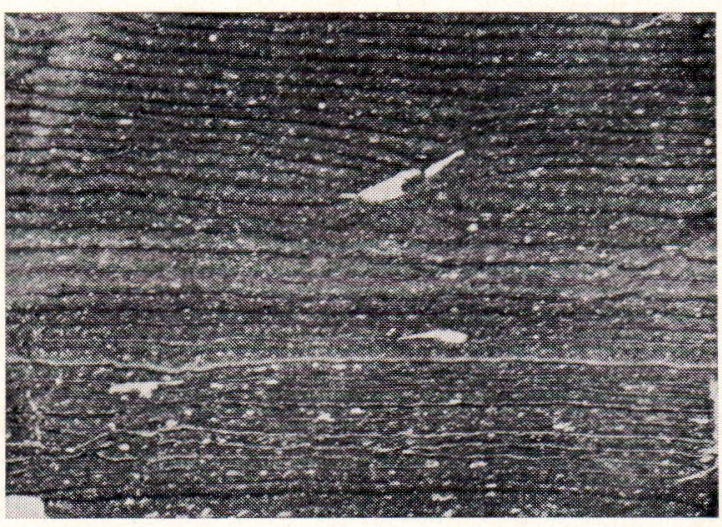

Fig. 1. The laminated sediment of Lake Valkiajärvi as revealed by a microphotograph of a thin section. Each light-dark couplet represents one year, i.e. a varve. Average varve thickness ca. $0.3 \mathrm{~mm}$. 
meromictic lake, the Lake of the Clouds in Minnesota, also contain thin dark-light annual laminations. Anthony (1977) has suggested that the precipitation of ferric iron due to the partial oxygenation of iron-rich bottom water during overturns, mainly in spring, gives rise to the light-coloured lamina, while the dark layer would represent organic remains that settle out during the summer. Thus the precipitation of iron emerges as the main constituent in the formation of these annual laminations.

The purpose of the present study was to test in the case of Lake Valkiajärvi whether the simple mechanism of seasonal variations in mineral matter deposition was superimposed upon seasonal changes in the precipitation of iron and some other elements. The use of an energy-dispersive X-ray microanalysis enabled the variations in silicon, iron, calcium, chlorine, potassium and sulphur within the laminations to be analysed, and their role in the formations of the laminations to be discussed. The element analyses were performed by the author T.A. in the Institute of Electron Optics at the University of Oulu.

\section{Lake Valkiajärvi and its sediment}

Lake Valkiajärvi is situated in the commune of Ruovesi in the Lake Region of Finland $\left(61^{\circ} 51^{\prime} \mathrm{N}\right.$ Lat., $23^{\circ} 53^{\prime} \mathrm{E}$ Long, elevation $110 \mathrm{~m}$ a.s.1.), in a granodioritic bedrock basin (cf. Matisto 1961). The lake is deep in comparison to its surface area of only $7.84 \mathrm{hec}-$ tares, having a mean depth of $8.4 \mathrm{~m}$ and a maximum depth of $25 \mathrm{~m}$. The following brief listing of its limnological parameters follows Meriläinen (1970).

Lake Valkiajärvi is meromictic, i.e. permanently chemically stratified. The sharply defined, stable chemocline at $17 \mathrm{~m}$ separates the upper mixolimnion from the monimolimnion. The former accounts for $93.4 \%$ and the latter $6.6 \%$ of the total water volume of the lake. The mixolimnion undergoes mixing during spring and autumn overturns (not complete in Lake Valkiajärvi), and oxygen is present in abundance, whereas the amounts of dissolved substances are low. The monimolimnion is highly stable, with hardly any mixing. It contains high concentrations of dissolved substances, but is entirely lacking in oxygen throughout the year. The high specific conductivity ( $\max .1370 \mu \mathrm{S})$ indicates an enrichment of dissolved salts in the monimolimnion. As a consequence of its high bicarbonate content, the monimolimnion is also rich in total $\mathrm{CO}_{2}$. Similarly the $\mathrm{pH}$ rises somewhat in the monimolimnion, although the reaction is acid throughout the water column.

By virtue of its mixolimnion Lake Valkiajärvi is an unproductive oligotrophic lake. Primary production of phytoplankton is small and the macrophytic aquatic vegetation is poorly developed.

The high concentration of iron (max. 380 mg per litre) suggests that this is the most important factor responsible for the permanent chemical stratification of Valkiajärvi. Manganese (max. $10 \mathrm{mg}$ per litre) and calcium also contribute markedly to the stability of the monimolimnion. Concentrations of calcium, potassium, sodium, silicon and ammonia in monimolimnion are about 40, 9, 4, 7, and 22 times as great, respectively, as in the mixolimnion.

Iron is practically insoluble in the mixolimnion because of the high oxygen concentration, whereas in the monimolimnion iron remains in solution in the form of ferrous bicarbonate because of the lack of oxygen, the presence of sufficient amounts of carbon dioxide, a $\mathrm{pH}$ around 6.5 , and organic material as a reducing agent for ferric hydroxide. In addition, the concentration of hydrogen sulphide $\left(\mathrm{H}_{2} \mathrm{~S}\right)$ must be low. This is the case in the unproductive Lake Valkiajärvi, as 
hydrogen sulphide is largely produced by decomposing organic matter.

The iron content in the meromictic Lake of the Clouds is higher than in Lake Valkiajärvi (maximum $620 \mathrm{mg}$ and $380 \mathrm{mg}$ per litre respectively), and the chemocline is not so sharp and stable as in Lake Valkiajärvi, and is situated only about $2 \mathrm{~m}$ above the bottom at $31 \mathrm{~m}$. The monimolimnion in the Lake of the Clouds is very small in area and undergoes at least partial oxygenation and mixing during overturns (Anthony 1977).

The sediments of Lake Valkiajärvi were sampled only in the area below the chemocline, where the organic sediment sequence is nearly 3 metres in thickness. This rests on a massive sand layer of varying thickness $(1-10 \mathrm{~cm})$. Further down, the sediment is composed of thinly varved clay to an unknown depth. The organic sediment is consistently laminated throughout its entire thickness, with an average varve thickness of $0.3 \mathrm{~mm}$, thus representing a sedimentary record covering nearly 9000 years. The varves are somewhat thicker near the bottom than higher up, and short-term fluctuations in varve thickness also occur elsewhere. The thicker varves are normally lighter in colour, and in some cases they contain vast quantities of diatoms, whereas the thinner varves are brownish-black. The loss-on ignition increases from $5 \%$ at the bottom up to 40 to $50 \%$ for the main part of the sediment. Vivianite $\left[\mathrm{Fe}_{3}\left(\mathrm{PO}_{4}\right)_{2} \cdot 8 \mathrm{H}_{2} \mathrm{O}\right]$ is abundant in the lower sediment sequence, its small, white nodules (which become blue upon oxidation) being observable mostly in the dark, humusrich winter layers.

\section{Laboratory studies}

The material used in the present study was sampled with a $90-\mathrm{mm}$ diameter PVC-tube piston corer (Core Va-75) from the deepest
$(25 \mathrm{~m})$ part of the lake. A piece of fresh sediment (surface area $2 \times 2 \mathrm{~cm}$ ) in which the varves were reasonably clear was dried at room temperature and the dry sample immersed in the impregnating medium (EPOFIX) under a vacuum. Polished thin sections were made using a procedure modified from the method of Moreland (1968). The electrical conductivity necessary for microanalysis was achieved by a thin surface layer of vacuum-evaporated carbon.

\section{Microanalysis technique}

The microanalyses were performed using a JEOL JSM-35 scanning electron microscope (SEM) equipped with PGT DELTA XCEL energy dispersive spectrometer (EDS). The main problem in analysing loose, humus-rich material is specimen damage caused by the electron beam. This effect is much less pronounced when using an SEM + EDS combination, however, than in the case of an SEM equipped with crystal spectrometers or in a conventional microprobe, both of which need a beam current of 100 times the magnitude of the SEM + EDS.

Preliminary qualitative microanalyses were carried out first, in which approximately 1 sq. $\mathrm{mm}$ of the specimen surface was scanned by the electron beam, and the whole X-ray spectrum from about $1 \mathrm{keV}$ to $20 \mathrm{keV}$ was recorded by the EDS. The elements iron, calcium, potassium, chlorine, sulphur and silicon were detected in the spectrum.

These elements were then studied by means of a digital line profile analysis, in which the characteristic X-ray lines of the elements were simultaneously mapped along a single line. The electron beam of the SEM was moved digitally step by step across the sample, and data for each element were collected from exactly the same points on the scan line. The time for one complete pass was 1000 seconds and the number of points 

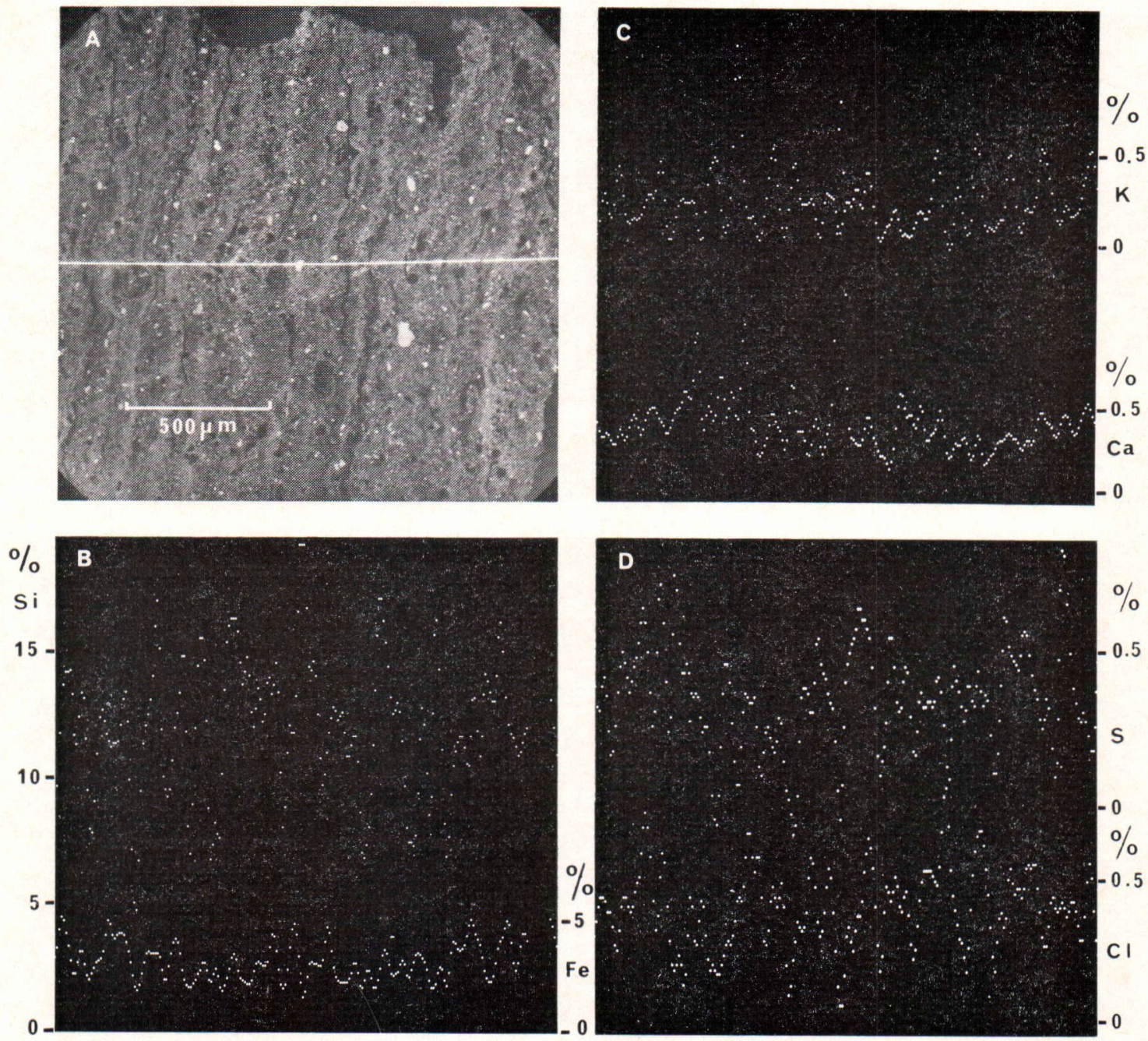

Fig. 2. Backscattered electron image of laminated sediment (A), and digital line scans of Si and Fe (B), $\mathrm{K}$ and $\mathrm{Ca}(\mathrm{C})$, and $\mathrm{S}$ and $\mathrm{Cl}(\mathrm{D})$. The centre line on the backscattered electron image represents the analysis line across the sample. The original magnification of the scanning electron microscope was $47 x$.

analysed was 256 . The step intervals in the two-line profiles were 7.2 and 3.7 microns, respectively.

The measurement data stored in the memory of the EDS were then transferred to the cathode - ray tube of the SEM, and the distribution patterns of the elements analysed were photographed. These results are presented in Figs. 2-3. Semiquantitative weight percentage scales were calculated, and are also shown in the figures.

\section{Results}

The distribution patterns presented in Figs. 2 and 3 suggest that silicon and potassium, and to some extent also calcium, vary in a broadly similar manner. This involves a major periodicity of the same order as that in the varves themselves, marked by pronounced peaks in concentration, and a minor periodicity corresponding in frequency to that observable in the iron content. The 

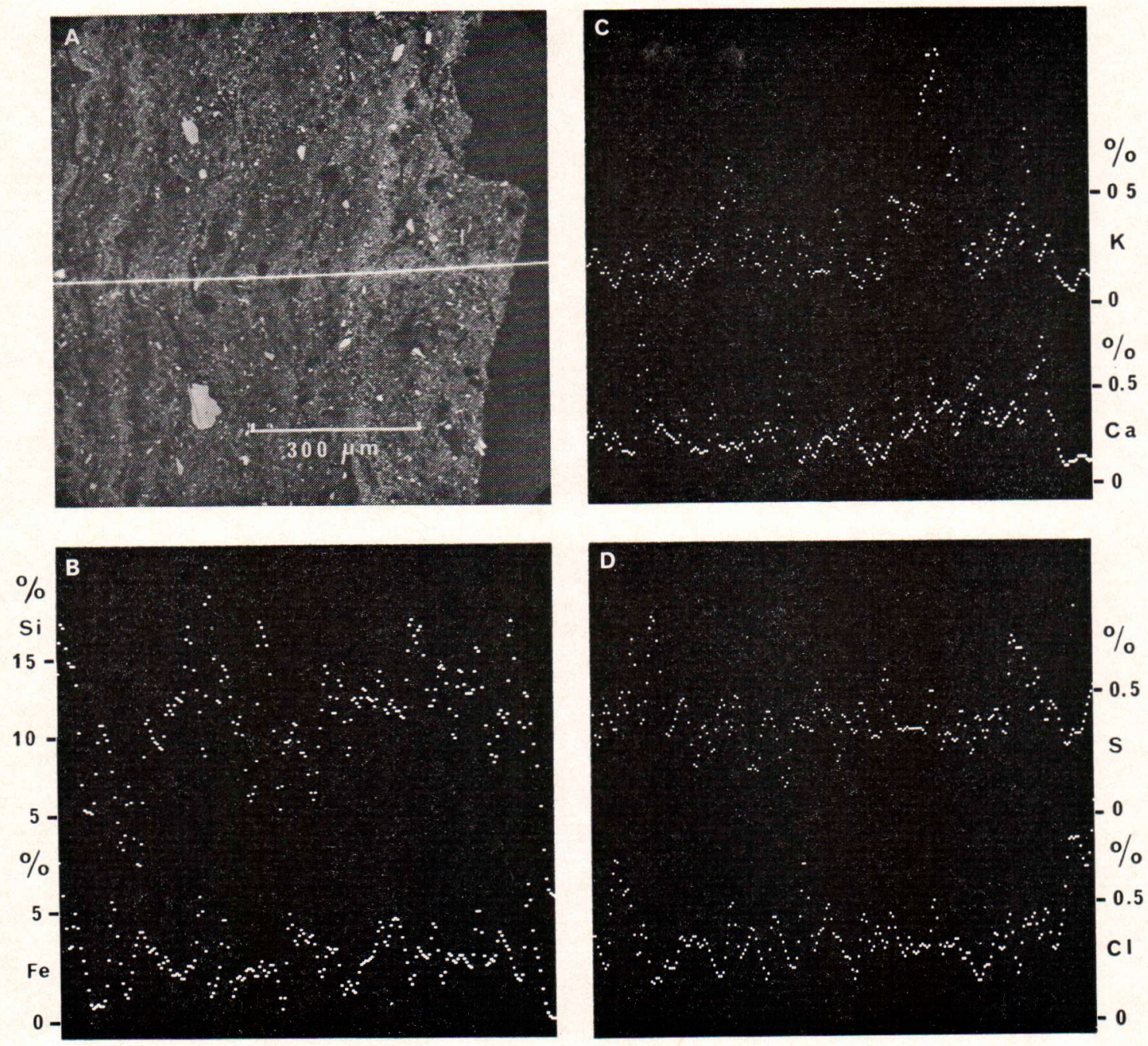

Fig. 3. An enlarged detail from Fig. 2. The original magnification of the scanning electron microscope was $90 x$.

concentrations of silicon vary in the range $1-15 \%$, iron in the range $0.5-5 \%$ and chlorine, sulphur, calcium and potassium in the range $0.1-0.6 \%$. Silicon and iron also show high peaks due to detrital mineral grains.

The variations in chlorine, which is derived from the impregnating medium, largely reflect the porosity of the sample. As a consequence of the relatively high chlorine concentration in this impregnation material, no indication is obtained of any possible occurrence of chlorine in the sediment itself. The sulphur present also originates in part from the impregnating medium, but the peak values from $0.5 \%$ up, which coincide with the minimum levels of silicon, are higher than those seen at the margins of the figure, which represent the impregnating medium alone, so that they must denote actual sulphur concentrations present in the sediment.

The concentrations of manganese are so 
low that they cannot be detected by energydispensive microanalysis, although figures of $0.1-0.3 \%$ are obtained using a microprobe equipped with a crystal spectrometer, and the values may be considerably higher in certain very narrow peaks which coincide with peaks in iron concentration.

\section{Conclusions}

Silicon, the most abundant element in the sediment of Lake Valkiajärvi after organic matter, shows rhythmic changes comparable with the suggested varve thickness of $0.3 \mathrm{~mm}$, while the variation in potassium seems to be closely connected with that of silicon, possibly indicating that these are partly derived from feldspars and micas, and are thus of detrital origin. Quartz grains are obviously the main source of silicon, however, although also originating in part from dissolved diatom frustules (Meriläinen 1970). Diatom blooms are associated with a high Si content in the water, and are thus superimposed on the rhythmic changes in the quantity of minerogenic silicon. Large mineral grains produce erratic, non-rhythmic variations in the element content of some lamina, thus disturbing to some extent the impression of a highly regular lamination, as seen in Fig. 1, for example.

Iron remains low and does not show any rhythmic changes which could be related to the visual changes in the sediment. Iron in the sediments of Lake Valkiajärvi has clearly smaller values than in light laminae in the Lake of the Clouds where it rises to over $20 \%$ in places (Anthony 1977). Oxygenation of the iron-rich bottom water seems to be a prerequisite for iron-rich laminae in the sediments, as is the case in the Lake of the Clouds (see also Renberg 1979). Under the reducing conditions prevailing in the monimolimnion of Lake Valkiajärvi, only a plentiful supply of $\mathrm{H}_{2} \mathrm{~S}$ could precipitate ferrosulphide in the sediments (see description of the limnology of Lake Valkiajärvi). Sulphur remains low here, however, and reaches its maximum values when silicon is low, i.e. in the humus-rich laminae. It may therefore be suggested that the iron in the monimolimnion originates from outside the lake rather than by dissolving out from the sediment. Iron compounds are highly insoluble under the stable conditions prevailing in the monimolimnion (see discussion in Meriläinen 1970, also Kjensmo 1967: 294-299).

In addition to iron, manganese and calcium are abundantly present in the monimolimnion (Meriläinen 1970). Manganese is hardly detectable in the sediment, however, and the calcium values are also low. The origin of these in the bottom water must thus also lie outside the lake. Calcium together with silicon, iron, and potassium mostly originate from weathering products of the surrounding granodioritic bedrock.

To sum up, the macroscopically observable thin laminations in Lake Valkiajärvi reflect seasonal variations in mineral matter deposition, the highest amounts being transported by spring floods after the melting of the ice. The proportion of organic matter increases as winter approaches, the season when the sulphur content of the sediment is at its highest.

A scanning electron microscope equipped with an energy dispersive spectrometer, as used as routine equipment in mineralogy and metallurgy, is a fast and rather accurate tool for investigating loose, humus-rich sediments. Thus equipped, the SEM combines its usual imaging ability with some of the analytical advantages of an electron microprobe and is an effective instrument also in sedimentology.

Acknowledgements - We thank Mr. Seppo Sivonen for critically reading part of the manuscript and for providing valuable suggestions, 
Dr. Gunnar Digerfeldt for reading the manuscript, Mrs. Ulla Paakkola for making the thin sections, Mrs. Raija Peura and Mrs. Sinikka Komulainen

\section{References}

Anthony, R. S. (1977) Iron-rich rhythmically laminated sediments in Lake of the Clouds, northeastern Minnesota. Limnol. Oceanogr. 22 (1), 45-54.

Kjensmo, J. (1967) The development and some main features of »iron-meromictic» soft water lakes. Arch. Hydrobiol. Suppl. 32: 137-312.

Koivisto, E. and Saarnisto, M. (1978) Conventional radiography, xeroradiography, tomography, and contrast enhancement in the study of laminated sediments. Preliminary report. Geog. Ann. Vol. $60 \mathrm{~A}, 55-61$.

Matisto, A. (1961) Geological map of Finland. Sheet 2213 Kuru. Explanation to the map of rocks. Geologinen tutkimuslaitos.

Meriläinen, J. (1970) On the limnology of the meromictic Lake Valkiajärvi, in the Finnish Lake District. Ann. Bot. Fennici 7: 29-51. for their help in the SEM + EDS- instrument operations, and Mr Malcolm Hicks for checking the English of the manuscript.

Moreland, G. C. (1968) Preparation of polished thin sections. Am. Mineral. 53, 2070-2074.

Renberg, I. (1979) Environmental monitoring by chemical, physical and biological analyses of annually -laminated lake sediments - the possibilities of the method. In: The use of ecological variables in environmental monitoring. The Natl. Swedish Environ. Prot. Board, Rep. PM 1151, 318-324.

Saarnisto, M. (1978) Annually laminated sediments of the lake Valkiajärvi. Lammi Notes 1, p. 6 .

- (1979) Studies of annually laminated lake sediments. In: Project guide, IGCP Project $158 \mathrm{~B}$, Lake and mire environments, Vol. 2. (ed B. E. Berglund), Lund, 61-80.

Manuscript received, June 3, 1980 